This is the Authors Accepted Manuscript of an article published in: Electrochimica Acta 137 (2014) 65-74. Available online 6 June 2014. The final version may be found at: https://doi.org/10.1016/j.electacta.2014.05.163

\title{
Zr-based conversion layer on Zn-Al-Mg alloy coated steel sheets: insights into the formation mechanism
}

\author{
Thomas Lostak ${ }^{\mathrm{a}}$, Artjom Maljusch ${ }^{\mathrm{b}, 1}$, Björn Klink ${ }^{\mathrm{b}, \#}$, Stefan Krebs ${ }^{\mathrm{a}}$, Matthias Kimpel ${ }^{\mathrm{a}}$, Jörg Flock ${ }^{\mathrm{a}}$, \\ Stephan Schulz ${ }^{\mathrm{c}}$, Wolfgang Schuhmann ${ }^{\mathrm{a}^{*}, 1}$ \\ a'ThyssenKrupp Steel Europe AG, Research and Development, Kaiser-Wilhelm-Straße 100, D-47166 Duisburg, Germany \\ ${ }^{b}$ Ruhr-Universität Bochum, Analytical Chemistry - Center for Electrochemical Sciences (CES), \\ Universitätsstr. 150, D-44780 Bochum, Germany \\ cUniversität Duisburg-Essen, Faculty of Chemistry, Universitätsstr. 7, D-45141 Essen, Germany \\ \#present address: Max-Planck Institute of Molecular Physiology, Structural Biology Group, \\ Otto-Hahn-Str. 11, D-44227 Dortmund, Germany
}

\begin{abstract}
Zr-based conversion layers are considered as environmentally friendly alternatives replacing trication phosphatation in the automotive industry. Based on excellent electronic barrier properties they provide an effective corrosion protection of the metallic substrate. In this work, thin protective layers were grown on novel $\mathrm{Zn}-\mathrm{Al}-\mathrm{Mg}$ alloy coated steel sheets by increasing the local $\mathrm{pH}$-value at the sample surface leading to deposition of a Zr-based conversion layer. For this purpose $\mathrm{Zn}-\mathrm{Al}-\mathrm{Mg}$ alloy $(\mathrm{ZM})$ coated steel sheets were treated in an aqueous model conversion solution containing well-defined amounts of hexafluorozirconic acid $\left(\mathrm{H}_{2} \mathrm{ZrF}_{6}\right)$ and characterized after different immersion times with SKPFM and field emission SEM (FE-SEM)/EDX techniques. A deposition mechanism of Zr-based conversion coatings on microstructural heterogeneous $\mathrm{Zn}-\mathrm{Al}-\mathrm{Mg}$ alloy surfaces was proposed.
\end{abstract}

Keywords: $\mathrm{Zn}-\mathrm{Al}-\mathrm{Mg}$ alloy coated steel sheets, $\mathrm{ZrO}_{2}$, conversion layer, SKPFM, SEM/EDX

*corresponding author: Wolfgang Schuhmann; Email: wolfgang.schuhmann@rub.de, tel. +49 2343226200

${ }^{1}$ ISE member 


\section{Introduction}

Classical industrial pre-treatment systems based on phosphates [1] and chromates [2] are used to improve the corrosion resistance of metal substrates and provide good adhesion properties for organic coatings. However, there are serious disadvantages of this pre-treatment chemistry which are their toxicology, inefficient process parameters and their high environmental impact [3]. Accordingly, new eco-friendly pre-treatment systems were developed in the last few years. Beside silanes [4-9] as coupling agents and corrosion inhibitors, zirconium based systems [10-13] are promising alternatives to replace harmful pre-treatment technologies in the field of metal finishing. In the industrial area predominantly hexafluorozirconic acid $\left(\mathrm{H}_{2} \mathrm{ZrF}_{6}\right)$ solutions [24] are used to form the conversion coating on the metal surface. It was found, that the deposited layer mostly consists of $\mathrm{ZrO}_{2}$, fluorine and small quantities of metal ions from the metallic substrate [23]. Electrochemical investigations (potentiodynamic polarization experiments [19], electrochemical impedance spectroscopy measurements, in situ height-regulated scanning kelvin probe studies [23]) clearly demonstrated very good corrosion protection performance of $\mathrm{Zr}$-based conversion layers on different alloys and significantly decreased kinetics of the delamination of polymer coatings deposited on zinc surfaces [23].

In many cases, the precipitation of the conversion layer requires the dissolution of the alloy and a subsequent alkalization of the electrolyte in close proximity to the sample surface. Different studies reported that the formation of these ultra-thin conversion coatings highly depends on the microstructure of the alloy composition, which mainly determines the electrochemical behaviour of the metal surface. Nordlien et al. [16] showed that the preferred deposition of the zirconium oxide layer on aluminium alloys occurred on and around intermetallic particles (IMP) due to specific cathodic reactions like hydrogen evolution and oxygen reduction, resulting in a reduced cathodic activity of the IMPs. In consequence, the 
further growth of the pre-treatment layer stopped and the metal substrate was not completely covered. The different stages of the film formation process in the $\mu \mathrm{m}$ range were examined by Andreatta et al. [19] using a scanning kelvin probe force microscope (SKPFM). This spaceresolved technique combines atomic force microscopy (AFM) with scanning Kelvin probe (SKP) microscopy. The lateral resolution of this technique is better than $0.1 \mu \mathrm{m}$ compared to standard SKP [25-27]. During the first seconds in the conversion bath, the native oxide layer was dissolved by free fluoride ions in the bath. Subsequently, the initial growth of the corrosion protection layer started on the incorporated $\alpha-\mathrm{Al}(\mathrm{Fe}, \mathrm{Mn}) \mathrm{Si}$ IMPs. In contrast to the studies by Nordlien et al. [16] the conversion coating covers progressively the complete surface. The formation of the coating decreases the Volta potential difference between the noble IMPs and the surrounding aluminum matrix with longer immersion times. In accordance to these investigations, Verdier et al. [22] were applying high-resolution scanning electron microscope (HRSEM)/energy dispersive x-ray spectroscopy (EDX) and could show, that the layer formation starts on the cathodic phases (manganese-rich particles) of the used $\mathrm{Mg}-6 \%$ Al alloy.

Based on these results, it seems to be very important to understand the substrate depending formation mechanism in order to develop eco-friendly conversion coatings, which are comparable in their protection properties to established conversion layers such as trication phosphatation or chromate passivation. The combination of SKPFM and SEM/EDX provides a powerful tool to identify cathodic and anodic areas in the heterogeneous structures of different alloy surfaces [19, 28].

In this contribution, $\mathrm{Zn}-\mathrm{Al}-\mathrm{Mg}$ alloy (ZM) coated steel sheets were chosen as substrates because they exhibit enhanced corrosion protection properties relative to conventional hot dipped galvanized steel sheets (HDG) [29]. Therefore, this material is of major interest in a wide field of technological applications such as the automotive and building industry. In 
contrast to conventional HDG surfaces or aluminium alloys, these coatings are multiphase systems with a challenging heterogenic microstructure. For instance, the used ZM consists of a zinc rich phase, an aluminum phase and a magnesium rich phase. The latter consists of the intermetallic phase $\mathrm{MgZn}_{2}$. It is assumed that various phases may react differently with the conversion solution leading to a non-uniform conversion layer deposition process.

The aim of this work is to gain insight into the deposition mechanism of Zr-based conversion layers on novel Zn-Al-Mg alloys. For this purpose, ZM substrates were treated in an aqueous model conversion solution containing well-defined amounts of hexafluorozirconic acid and subsequently characterized after different immersion times using SKPFM and FESEM)/EDX. A possible deposition mechanism of Zr-based conversion coatings on the microstructural heterogeneous ZM surfaces can be postulated.

\section{Experimental}

\subsection{Zn-Al-Mg coated steel sheets}

The used steel samples were supplied by ThyssenKrupp Steel Europe AG. The specimens have been made at laboratory scale using a hot dip process simulator (Rhesca, Japan). The ZnAl-Mg coating (ZM) contains $90.26 \% \mathrm{Zn}, 3.97 \% \mathrm{Al}$ and $5.78 \% \mathrm{Mg}$ by weight. The average coating thickness is $7 \mu \mathrm{m}$.

\subsection{Deposition of conversion layer}

The conversion solution contains $1 \mathrm{mM}$ hexafluorozirconic acid solution (Alufinish, Germany). In order to follow the deposition process of the conversion layer (CL) with improved time resolution, the conversion solution was diluted 10 times up to final concentration of $0.1 \mathrm{mM} \mathrm{H}_{2} \mathrm{ZrF}_{6}$. The $\mathrm{pH}$-value of the conversion solution was adjusted to $\mathrm{pH}$ 4 using ammonium bicarbonate as buffering agent. The immersion of the samples was performed without stirring at $T \sim 20^{\circ} \mathrm{C}$. After immersion of the samples into the conversion 
solution all substrates were rinsed with ultrapure water $\left(T \sim 20{ }^{\circ} \mathrm{C}, \kappa \leq 0.005 \mu \mathrm{S} / \mathrm{cm}\right)$ and dried in a stream of nitrogen.

\subsection{Indentation of the samples}

For reproducible positioning of the sample for sequential AFM and SKPFM measurements a set of indentations was made on the sample surface using the micro hardness tester LM247AT (Leco, USA). The proof load was $1 \mathrm{mN}$ for $5 \mathrm{~s}$. The indentation was performed with a conventional Vickers indenter $\left(136^{\circ}\right)$.

\subsection{AFM/SKPFM measurements}

A JPK Nanowizard III atomic force microscope system equipped with a KPM module (JPK, Germany) was used for AFM and SKPFM measurements. First, images were collected in tapping mode to trace the surface topography (AFM) and then the lateral distribution of the Volta potential difference (SKPFM) was visualized during the retrace scan of the same line with a $50 \mathrm{~nm}$ tip-to sample distance (so-called hover mode). All SKPFM measurements were performed using $\mathrm{Cr} / \mathrm{Pt}$ coated cantilevers (BudgetSensors Tap 300E-G, Innovative Solutions Bulgaria, Bulgaria). The resonance frequencies of these cantilevers were typically around $240 \mathrm{kHz}$ while the force constant was $40 \mathrm{~N} / \mathrm{m}$. During all AFM measurements the piezo Zrange of the AFM scanner was set to $7.5 \mu \mathrm{m}$ to enable high vertical resolution and a scan speed of $15 \mu \mathrm{m} / \mathrm{s}$ was used to collect initial images of $70 \mu \mathrm{m} \times 70 \mu \mathrm{m}$ in size with a resolution of 1024 x 1024 pixels.

\subsection{Surface analytical techniques}

\subsection{1. $X P S$}

The chemical compositions of the formed conversion layers were investigated using a Quantera II Scanning XPS Microprobe (Physical Electronics, USA). All spectra were 
obtained using a monochromatic $\mathrm{Al} \mathrm{K}_{\alpha}$-beam with a spot size of $100 \mu \mathrm{m}$ x $100 \mu \mathrm{m}$. The takeoff angle of the detected photoelectrons was $45^{\circ}$ to the surface normal. The $\mathrm{C} 1 \mathrm{~s}$ peak (binding energy of $284.8 \mathrm{eV}$ ) was used as internal reference for all spectra. The quantification of all elements was performed on the basis of survey spectra. Depth profiling was performed using $\mathrm{Ar}^{+}$ion sputtering with an acceleration voltage of $2 \mathrm{kV}$ and a sputter rate of $8.5 \mathrm{~nm} / \mathrm{min}$. A silicon wafer containing a well-defined oxide layer of known thickness was used for depth calibration. The fitting of the measured XPS spectra was performed using the CasaXPS software (Casa Software Ltd).

\subsection{2. $\quad F E-S E M / E D X$}

The compositional analysis of the Zn-Al-Mg alloy coated steel surface was performed with a high resolution FE-SEM Merlin ${ }^{\circledR}$ microscope (Carl Zeiss Microscopy, Germany) equipped with an EDX analysis device (EDAX Ametek, Germany). The microscope was equipped with an inlense detector. The working distance between the sample and the pole shoe was $2 \mathrm{~mm}$. The primary electron beam acceleration was $7 \mathrm{kV}$, which gives a surface near analysis depth.

\section{Results and Discussion}

SEM image of the cross-section of steel specimen coated with Zn-Al-Mg alloy (ZM) are shown in figure 1. The ZM layer is a heterogeneous layer that consists of different phases: a primary zinc phase, an aluminum rich phase and the binary eutectic phase $\mathrm{MgZn}_{2}-\mathrm{Zn}$. The presence of a small amount of aluminum leads to the formation of a very thin Al-Fe alloy layer at the steel/alloy coating interface, thus preventing the formation of brittle $\mathrm{Zn}-\mathrm{Fe}$ intermetallics.

Figure 1. SEM micrograph of the cross-section of a steel substrate coated with a ZM layer. 
Prior to experiments, sets of indentations with different sizes and depths were made on the sample surface to mark the area of interest (Fig. 2A). First, one big and deep indentation was used for a visual pre-positioning of the sample on the sample holder of the AFM system. After that, an optical microscope was used for more precise alignment of the area of interest according to the scanning area of the AFM based on two or four small micro-indentations made on the sample surface. This procedure was repeated after each immersion experiment to ensure AFM measurements over the same area on the sample surface during each experiment. Figure 2B represents the SEM image of the sample surface marked with four microindentations. The sample surface exhibits a very inhomogeneous structure with many small phases separated from each other by phases with different chemical composition.

Figure 2. Photographic image of the sample surface with a set of one big and four small micro-indentations (A). The red dotted rectangle is marking the area on the sample surface investigated using SEM (B).

To investigate the chemical composition of all phases present on the sample surface twodimensional EDX mapping (2D-EDX) was performed over the same area as visualized by SEM (Fig. 3). Figure 3A represents the distribution of Zn over the area of interest. Two types of phases can be identified; bigger phases which are enriched with $\mathrm{Zn}$ and many small phases around them with a lower amount of $\mathrm{Zn}$. Figure 3B represents the distribution of $\mathrm{Mg}$ and reveals the presence of areas enriched with $\mathrm{Mg}$ as also Mg-rich and Mg-pure areas. The distribution of $\mathrm{Al}$ is represented in figure 3C. Overlaying all three EDX mappings shows that the big phases enriched with $\mathrm{Zn}$ have a rather low amount of $\mathrm{Al}$ and $\mathrm{Mg}$ ( $\mathrm{Zn}$-rich phases). The middle size phases are enriched with $\mathrm{Mg}$ and are localized close to the $\mathrm{Zn}$-rich phases. These phases contain a certain amount of $\mathrm{Zn}$, but almost no Al (Mg-rich phases). Around the Zn-rich 
and the Mg-rich phases many small phases which are rich in $\mathrm{Al}$ are located exhibiting a rather small amount of $\mathrm{Zn}$ and $\mathrm{Mg}$ (Al-rich phases).

Figure 3. 2D-EDX mappings of the ZM alloy surface performed over the area on the sample surface marked with red dotted rectangle as indicated in figure 2B. Figure 3A corresponds to $\mathrm{Zn}$, figure $3 \mathrm{~B}$ to $\mathrm{Mg}$ and figure $3 \mathrm{C}$ to $\mathrm{Al}$, respectively.

After 2D-EDX mapping a combined AFM/SKPFM measurement was performed over the marked area (Fig. 4). The AFM image (Fig. 4A) clearly shows the location of all four microindentations confirming the identity of scanned area with the one investigated using SEM and 2D-EDX. AFM reveals a very heterogeneous structure of the sample surface with topographical features of up to $1 \mu \mathrm{m}$ height. Most probably, these heterogeneous structures are the consequence of the sample fabrication procedure. The initially obtained rather thick layer of ZM formed on the sample surface after its movement through the coating bath was partially blown away by high pressure nozzles supplied with nitrogen gas to thin the coating up to approximately $7 \mu \mathrm{m}$. Figure 4B represents the result of the SKPFM measurement performed over the same area. The lateral distribution of the Volta potential difference is not sufficient to be visualized with a good contrast inside the marked area. We believe that this was caused by a thin layer of carbonaceous products deposited on the sample surface during EDX mapping. Additionally, because of the very heterogeneous structure of the sample surface, it was not possible to localize phases with different compositions based on differences in their topography. Therefore, the strategy was changed and the SEM imaging as well as EDX mapping of the sample surface was performed only after the final immersion experiment. 
Figure 4. AFM (A) and SKPFM (B) measurements performed directly after 2D-EDXmapping over a slightly bigger area as marked in figure 2B.

The influence of the immersion time into the conversion solution on the lateral distribution of the Volta potential difference and the topography of the sample surface was investigated using AFM/SKPFM. For this, a set of AFM/SKPFM measurements was performed over the same area on an as fabricated sample surface prior to the deposition of the conversion layer and sequentially after each immersion of the sample in the conversion bath with different concentrations $\left(0.1 \mathrm{mM}\right.$ and $1 \mathrm{mM} \mathrm{H}_{2} \mathrm{ZrF}_{6}$ solution $)$ and for different total immersion time ranging from $10 \mathrm{~s}$ to $404 \mathrm{~s}$. Figure 5 represents results of AFM (A, B) and SKPFM (C-F) measurements performed over the marked area on the as fabricated sample $(\mathrm{A}, \mathrm{C})$ and after immersion of the sample in the diluted conversion bath for $10 \mathrm{~s}$ (D) and $40 \mathrm{~s}(\mathrm{E})$. Figure $5 \mathrm{~B}$ and 5F represent results of AFM and SKPFM measurements performed on the sample which was immersed for $80 \mathrm{~s}$ in the diluted conversion bath followed by immersion for another $324 \mathrm{~s}$ in the $1 \mathrm{mM}$ conversion bath. Almost no changes of the sample topography were observed using AFM even after a total immersion time of more than $400 \mathrm{~s}$. This indicates rather small thickness of the deposited conversion layer. The lateral distribution of phases with different compositions was visualized with a good resolution using SKPFM. However, deposition of the conversion layer let to increased blurring of SKPFM images after each additional coating experiment. Additionally, as many phases with different compositions are placed close to each other and changes of their nobility were different in subsequent experiments, the visual comparison was rather complicated.

Figure 5. AFM (A, B) and SKPFM (C-F) measurements performed on an as fabricated sample $(\mathrm{A}, \mathrm{C})$ and after (B, D-F) deposition of the zirconium-based conversion layer for $10 \mathrm{~s}(\mathrm{D})$, $40 \mathrm{~s}(\mathrm{E})$ and $404 \mathrm{~s}(\mathrm{~B}, \mathrm{~F})$ on the ZM substrate. 
To correlate the lateral distribution of the contact-potential differences obtained by SKPFM of different phases with their composition, 2D-EDX mapping was performed over the marked area after the final immersion experiment (Fig. 6). Figure 6 represents the distribution of $\mathrm{Zn}(\mathrm{A}), \mathrm{Mg}(\mathrm{B})$ and $\mathrm{Al}(\mathrm{C})$ on the sample surface. Overlapping figure 5C (SKPFM data recorded on the surface of the as fabricated ZM substrate) and figure 6A (2D-EDX mapping of $\mathrm{Zn}$ ) revealed $\mathrm{Zn}$-rich phases as being comparatively noble phases, visualized using SKPFM as darker areas. Mg-rich and Al-rich phases appeared to be less noble visualized as brighter areas. Prior to the surface treatment with the conversion solution, the relative Volta potential difference over Mg-rich phases was about $300 \mathrm{mV}$ less noble than that of the most noble $\mathrm{Zn}$ rich phases. At the same time, Al-rich phases showed lower nobility than the Zn-rich phases, but they were nobler than Mg-rich phases. The observed distribution of nobility has a similar trend to the data reported by Schmutz et al. [25] for pure $\mathrm{Zn}, \mathrm{Mg}$ and $\mathrm{Al}$ samples. However, the absolute difference between values obtained for the relative Volta potential differences is much smaller. This indicates the presence of a thin layer of corrosion products as well as of a layer of native $\mathrm{Al}$ oxide on the sample surface already after a short time after the production of the ZM substrate.

Figure 6. 2D-EDX mapping performed over the same area on the sample surface as investigated by AFM/SKPFM. Measurement was performed after the final coating step. $\mathrm{Zn}$ (A), $\mathrm{Mg}(\mathrm{B})$ and $\mathrm{Al}(\mathrm{C})$.

To qualitatively investigate changes of relative nobility of the sample surface during the coating experiments, digital data processing of the AFM and SKPFM images was performed. First, all images were corrected by a polynomial fit independently applied to each line to eliminate the influence of the tilt of the sample on the AFM data and a color-coded Z-range was set to an identical signal range for all data sets (the measured height in the AFM images 
was set between 0 and $810 \mathrm{~nm}$ and the measured Volta potential difference as determined by SKPFM was set between $-100 \mathrm{mV}$ and $+200 \mathrm{mV}$ ). Second, all images were overlaid to an identical sample position using two micro-indentations, which were clearly visible on all images, as base points for alignment. To do so, all images were imported as individual objects to the raster graphics editor Photo-Paint (Corel, Germany) and aligned pixel by pixel to each other. Third, the 2D-EDX maps for $\mathrm{Zn}, \mathrm{Mg}$ and $\mathrm{Al}$ were converted to binary (black and white) images using the open source program package ImageJ (www.rsb.info.nih.gov/ij).

Figure 7. Binary images (black and white, lower row) representing the lateral distribution of each chemical element. As basis for these procedure 2D-EDX mapping results obtained after the last immersion experiment were used (upper row).

After that, the binary images were imported to the graphics editor and aligned to AFM and SKPFM images again using the two micro-indentations as base points. The aligned images were truncated to an image with a size of $\sim 65 \mu \mathrm{m} \times 63.5 \mu \mathrm{m}$, which was the biggest intersecting data set for all images recorded over the same area on the sample surface. Finally, binary 2D-EDX images, which contain information about the distribution of each metal, were used as masks for creation of fractional SKPFM images (Fig. 8). The fractional SKPFM images contain only parts of SKPFM images in which only those Volta potential differences are shown that were measured over areas on the sample surface enriched with the metal in question.

Figure 8. Deconvolution of SKPFM images visualizing the element-selective distribution of the Volta potential difference values on the sample surface over areas enriched mainly with one element. Selective SKPFM images were created using fractional 2D-EDX maps for single 
elements and the SKPFM image recorded over the marked area on the as fabricated ZM substrate.

Figure 9 represents selective SKPFM images corresponding to areas on the sample surface mainly enriched with $\mathrm{Zn}$ (top), $\mathrm{Mg}$ (centre) and $\mathrm{Al}$ (bottom). All images are arranged according to increased immersion time starting with the as fabricated ZM substrate on the left side and the longest immersion time placed on the right side. Even after short immersion in diluted conversion bath the nobility of different phases significantly changed. The difference in nobility between $\mathrm{Zn}$-rich and Mg-rich phases almost completely dissipated while Al-rich phases became the least noble ones. The reason for this could be a galvanic coupling between Zn-rich and Mg-rich phases. As Zn-rich phases are nobler than Mg-rich phases, they behave as local cathodes leading to reduction of dissolved oxygen and to local alkalization of a thin electrolyte layer in close proximity to the surface. The change of the local $\mathrm{pH}$ value led to precipitation of the protective Zr-based conversion layer [15,16,30], which acts as a barrier layer for further oxygen reduction on the underlying sample surface [23]. Therefore, the formation of the conversion layer predominantly on the surface of $\mathrm{Zn}$-rich phases was leading to a decrease in the local corrosion potential and concomitantly to a decrease in nobility of Zn-rich phases as visualized using SKPFM [31-33]. At the same time, Mg-rich phases displayed a selective dissolution leading to an enrichment of originally $\mathrm{Mg}$-rich phases with $\mathrm{Zn}$, as a certain amount of $\mathrm{Zn}$ was revealed by EDX to be also present in the Mg-rich phases. Al-rich phases almost do not display any changes in nobility, as the immersion time was not sufficiently long for the dissolution of the native Al oxide layer. Further increase of the total immersion time up to $40 \mathrm{~s}$ led to a further increase in the nobility of Mg-rich phases while the nobility of Zn-rich phases continued to slowly decrease. Finally, some of the partially dissolved Mg-rich phases appeared to be more noble than the Zn-rich phases and became local cathodes. A minor increase of the nobility of Al-rich phases was also observed. 
Immersion of the sample for even longer times $(80 \mathrm{~s})$ led to an inversion of the relative nobility of the phases. Mg-rich phases became less noble than the Zn-rich phases. One of the reasons could be precipitation of the Zr-based conversion layer predominantly on the Mg-rich phases as they became sufficiently enriched with $\mathrm{Zn}$ leading to pronounced oxygen reduction and corresponding local alkalization of the electrolyte. Long time immersion in the $1 \mathrm{mM}$ conversion bath does not change the relative nobility of the phases and only led to slight increase of the nobility of the Al-rich phases as a consequence of their partial dissolution and the possible slight enrichment with $\mathrm{Zn}$.

Figure 9. Selective SKPFM images corresponding to areas on the sample surface mainly enriched with $\mathrm{Zn}$ (top), $\mathrm{Mg}$ (centre) and $\mathrm{Al}$ (bottom) as a function of immersion time into the conversion solution (the immersion time is indicated).

Figure 10 represents results of 2D-EDX mapping performed over the marked area after the final immersion experiment. For a better overview figure 10A represents the lateral distribution of $\mathrm{Zn}, \mathrm{Al}$ and $\mathrm{Mg}$ while figure 10B represents the lateral distribution of $\mathrm{Zr}$. The $\mathrm{Zn}$-rich phases are obviously completely covered with Zr-containing products while a rather small amount of $\mathrm{Zr}$ is present on the surface of $\mathrm{Mg}$ - and Al-rich phases.

Figure 10. Single element 2D-EDX mapping performed over the marked area after the final immersion experiment. Figure 10A represents the lateral distribution of $\mathrm{Zn}, \mathrm{Mg}$ und $\mathrm{Al}$ while Figure 10B shows the lateral distribution of $\mathrm{Zr}$.

SKPFM/EDX clearly shows that the precipitation of the Zr-based conversion layer starts on the Zn-rich phases. Nevertheless, the precise composition of the deposited coating cannot be determined by EDX measurements. Therefore, additional XPS measurements were per- 
formed. Figure 11 shows the XPS sputter profile after deposition of the conversion coating after $300 \mathrm{~s}$ immersion time in the $1 \mathrm{mM}$ conversion solution. The depth profiles show that the main components of the conversion layer are oxygen and zirconium. Additionally, the zirconium oxide layer contains small amounts of fluorine from the $\mathrm{H}_{2} \mathrm{ZrF}_{6}$ solution (data not shown in Fig. 11). However, the XPS sputter profiles of single metals present in the ZM layer ( $\mathrm{Zn} 2 \mathrm{p} 3, \mathrm{Al} 2 \mathrm{p}, \mathrm{Mg} 2 \mathrm{p}$ ) confirm the proposed $\mathrm{ZrO}_{2}$ deposition mechanism. The corrosive conversion solution leads to a preferential anodic dissolution of the Mg containing phases in the alloy. In contrast to $\mathrm{Zn}$, the $\mathrm{Mg} 2 \mathrm{p}$ signal increases after sputtering of approximately $10 \mathrm{~nm}$ as compared to the $\mathrm{SiO}_{2}$ reference. The signal from the more noble aluminum increases already after $1.5 \mathrm{~nm}$. This layer structure in dependence on the nobility of the alloying elements after immersion in the conversion bath coincides perfectly with the results discussed above.

Figure 11. Single element XPS depth profile recorded on a sample treated in $1 \mathrm{mM} \mathrm{H}_{2} \mathrm{ZrF}_{6}$ conversion solution for $300 \mathrm{~s}$. Reference sputter rate: $\mathrm{R}\left(\mathrm{SiO}_{2}\right)=8.5 \mathrm{~nm} / \mathrm{min}$.

Based on previously discussed results a deposition mechanism of the protective Zr-based conversion layer can be proposed which is schematically presented in Figure 12. In the case of a short immersion time in a diluted conversion bath (up to $40 \mathrm{~s}$ ), the initially most noble Zn-rich phases act as local cathodes leading to local alkalization and predominant deposition of the CL on their surface. At the same time, the less noble Mg-rich and Al-rich phases display anodic dissolution leading to "enrichment" of the Mg-rich phases with Zn as a consequence of the exposure of $\mathrm{Zn}$ present in the Mg-rich phases. In the case of some Al-rich phases, this time was sufficiently long for the dissolution of native $\mathrm{Al}$ oxide layer as well as a partial dissolution of the Al-rich phases leading to exposure of $\mathrm{Zn}$ and subsequent deposition of a thin CL. At longer immersion times ( $>40 \mathrm{~s})$, Mg-rich phases enriched with zinc started to 
behave as local cathodes. Their increased activity towards oxygen reduction led to local alkalization and hence to a deposition of the CL on the surface of originally Mg-rich phases. Immersion in the $1 \mathrm{mM}$ conversion bath for longer times $(>80 \mathrm{~s})$ led to deposition of a thicker CL over the entire sample surface.

Figure 12. Schematic representation of the deposition mechanism of the protective Zr-based conversion layer on steel sheets coated with a thin layer of a $\mathrm{Zn}-\mathrm{Al}-\mathrm{Mg}$ alloy.

\section{Conclusion}

The formation mechanism of a protective Zr-based conversion layer on a steel substrate coated with a thin layer of a Zn-Al-Mg alloy was investigated using a set of EDX, AFM and SKPFM experiments. Measurements were performed on an as fabricated ZM substrate (as reference) and on a ZM substrate after immersion of the sample in a conversion bath at different concentrations of hexafluorozirconic acid for different immersion times. A set of micro-indentations made on the sample surface proved to be a reliable tool for reproducible alignment of the sample prior to each AFM and SKPFM area scans. Among all metallic phases present on the sample surface $\mathrm{Zn}$-rich phases were found to be most noble while Alrich phases are less noble. Both of them are nobler than Mg-rich phases. Upon immersion in diluted conversion solution for rather short times of up to $40 \mathrm{~s}$ the deposition of CL starts to take place preferentially on the local Zn-rich cathodes. Simultaneously, Mg-rich and some Alrich phases undergo anodic dissolution leading to their enrichment with $\mathrm{Zn}$. Upon longer immersion times of $>40 \mathrm{~s}$, the precipitation of CL starts to take place also on the Mg-rich phases acting as local cathodes as the exposed amount of $\mathrm{Zn}$ is already sufficient for local alkalization of a thin electrolyte. In the case of longer immersion time the precipitation of the CL is taking place all over the sample surface. 


\section{References}

[1] T. S. N. Sanakara Narayanan, Surface Pretreatment by Phosphate Conversion Coatings A Review, Rev. Adv. Mater. Sci. (2005) 130.

[2] F. Eppensteiner, M. Jenkins, Chromate conversion coatings, Metal Finish (2005) 367.

[3] Agency for Toxic Substance, U.S. Public Health Service, Toxicological Profile for Chromium, ATDSRyTP-88y10, 1989.

[4] M.G.S. Ferreira, R.G. Duarte, M.F. Montemor, A.M.P. Simões, Silanes and rare earth salts as chromate replacers for pre-treatments on galvanized steel, Electrochim. Acta 49 (2004) 2927.

[5] A. Franquet, C. Le Pen, H. Terryn, J. Vereecken, Effect of bath concentration and curing time on the structure of non-functional thin organosilane layers on aluminium, Electrochim. Acta 48 (2003) 1245.

[6] M.-G. Olivier, M. Fedel, V. Sciamanna, C. Vandermiers, C. Motte, M. Poelman, F. Deflorian, Study of the effect of nanoclay incorporation on the rheological properties and corrosion protection by a silane layer, Prog. Org. Coat. 72 (2011) 15.

[7] D. Wang, G.P. Bierwagen, Sol-gel coatings on metals for corrosion protection, Prog. Org. Coat. 64 (2009) 327.

[8] D. Zhu, W.J. van Ooij, Enhanced corrosion resistance of AA 2024-T3 and hot-dip galvanized steel using a mixture of bis-[triethoxysilylpropyl]tetrasulfide and bis[trimethoxysilylpropyl]amine, Electrochim. Acta 49 (2004) 1113.

[9] D. Zhu, W.J. van Ooij, Corrosion protection of metals by water-based silane mixtures of bis-[trimethoxysilylpropyl] amine and vinyltriacetoxysilane, Prog. Org. Coat. 49 (2004) 42.

[10] H. Li, K. Liang, L. Mei, S. Gu, S. Wang, Corrosion protection of mild steel by zirconia sol-gel coatings, J. Mater. Sci. Lett. 20 (2001) 1081.

[11] G. Gusmano, G. Montesperelli, M. Rapone, G. Padeletti, A. Cusmà, S. Kaciulis, A. Mezzi, R. Di Maggio, Zirconia primers for corrosion resistant coatings, Surf. Coat. Technol. 201 (2007) 5822.

[12] R. Di Maggio, L. Fedrizzi, S. Rossi, Effect of the chemical modification of the precursor of $\mathrm{ZrO}_{2}$ films on the adhesion of organic coatings, J. Adhes. Sci. Technol. 15 (2001) 793.

[13] L. Fedrizzi, F.J. Rodriguez, S. Rossi, F. Deflorian, R. Di Maggio, The use of electrochemical techniques to study the corrosion behaviour of organic coatings on steel pretreated with sol-gel zirconia films, Electrochim. Acta 46 (2001) 3715.

[14] O. Lunder, F. Lapique, B. Johnsen, K. Nisancioglu, Effect of pre-treatment on the durability of epoxy-bonded AA6060 aluminium joints, Int. J. Adhes. 24 (2004) 107.

[15] O. Lunder, C. Simensen, Y. Yu, K. Nisancioglu, Formation and characterisation of TiZr based conversion layers on AA6060 aluminium, Surf. Coat. Technol. 184 (2004) 278.

[16] J.H. Nordlien, J.C. Walmsley, H. Østerberg, K. Nisancioglu, Formation of a zirconiumtitanium based conversion layer on AA 6060 aluminium, Surf. Coat. Technol. 153 (2002) 72 . 
[17] P. Laha, T. Schram, H. Terryn, Use of spectroscopic ellipsometry to study Zr/Ti films on Al, Surf. Interface Anal. 34 (2002) 677.

[18] D. Chidambaram, C.R. Clayton, G.P. Halada, The role of hexafluorozirconate in the formation of chromate conversion coatings on aluminum alloys, Electrochim. Acta 51 (2006) 2862.

[19] F. Andreatta, A. Turco, I. de Graeve, H. Terryn, J.H.W. de Wit, L. Fedrizzi, SKPFM and SEM study of the deposition mechanism of $\mathrm{Zr} / \mathrm{Ti}$ based pre-treatment on AA6016 aluminum alloy, Surf. Coat. Technol. 201 (2007) 7668.

[20] P. Puomi, H.M. Fagerholm, J.B. Rosenholm, K. Jyrkäs, Comparison of different commercial pretreatment methods for hot-dip galvanized and Galfan coated steel, Surf. Coat. Technol. 115 (1999) 70.

[21] P. Puomi, H.M. Fagerholm, J.B. Rosenholm, R. Sipilä, Optimization of commercial zirconic acid based pretreatment on hot-dip galvanized and Galfan coated steel, Surf. Coat.Technol. 115 (1999) 79.

[22] S. Verdier, N. van der Laak, F. Dalard, J. Metson, S. Delalande, An electrochemical and SEM study of the mechanism of formation, morphology, and composition of titanium or zirconium fluoride-based coatings, Surf. Coat. Technol. 200 (2006) 2955.

[23] C. Stromberg, P. Thissen, I. Klueppel, N. Fink, G. Grundmeier, Synthesis and characterisation of surface gradient thin conversion films on zinc coated steel, Electrochim. Acta 52 (2006) 804.

[24] S. Adhikari, K.A. Unocic, Y. Zhai, G.S. Frankel, J. Zimmerman, W. Fristad, Hexafluorozirconic acid based surface pretreatments: Characterization and performance assessment, Advances in corrosion science for lifetime prediction and sustainability, Electrochim. Acta 56 (2011) 1912.

[25] P. Schmutz, G.S. Frankel, Characterization of AA2024-T3 by scanning kelvin probe force microscopy, J. Electrochem. Soc. 145 (1998) 2285.

[26] M. Nonnenmacher, J. Greschner, O. Wolter, R. Kassing (Eds.), Scanning force microscopy with micromachined silicon sensors, AVS, Boston, Massachusetts (USA), 1991.

[27] M. Nonnenmacher, O'Boyle, M. P., Wickramasinghe, H. K., Kelvin probe force microscopy, Appl. Phys. Lett. 58 (1991) 2921.

[28] A. Davoodi, J. Pan, C. Leygraf, S. Norgren, The Role of Intermetallic Particles in Localized Corrosion of an Aluminum Alloy Studied by SKPFM and Integrated AFM/SECM, J. Electrochem. Soc. 155 (2008) C211.

[29] C. Commenda, J. Pühringer, Microstructural characterization and quantification of $\mathrm{Zn}-$ Al-Mg surface coatings, Mat. Charac. 61 (2010) 943.

[30] P. Taheri, K. Lill, J.H.W. de Wit, J.M.C. Mol, H. Terryn, Effects of Zinc Surface AcidBased Properties on Formation Mechanisms and Interfacial Bonding Properties of Zirconium-Based Conversion Layers, J. Phys. Chem. C 116 (2012) 8426.

[31] L. Forget, J. Delhalle, Z. Mekhalif, Application of scanning Kelvin probe to study the corrosion protection of chromated hot-dip galvanized steel, Mater. Corros. 52 (2001) 181. 
[32] B. Wilson, N. Fink, G. Grundmeier, Formation of ultra-thin amorphous conversion films on zinc alloy coatings: Part 2: Nucleation, growth and properties of inorganicorganic ultra-thin hybrid films, Electrochim. Acta 51 (2006) 3066.

[33] G. Klimow, N. Fink, G. Grundmeier, Electrochemical studies of the inhibition of the cathodic delamination of organically coated galvanised steel by thin conversion films, Electrochim. Acta 53 (2007) 1290. 
Figure 1

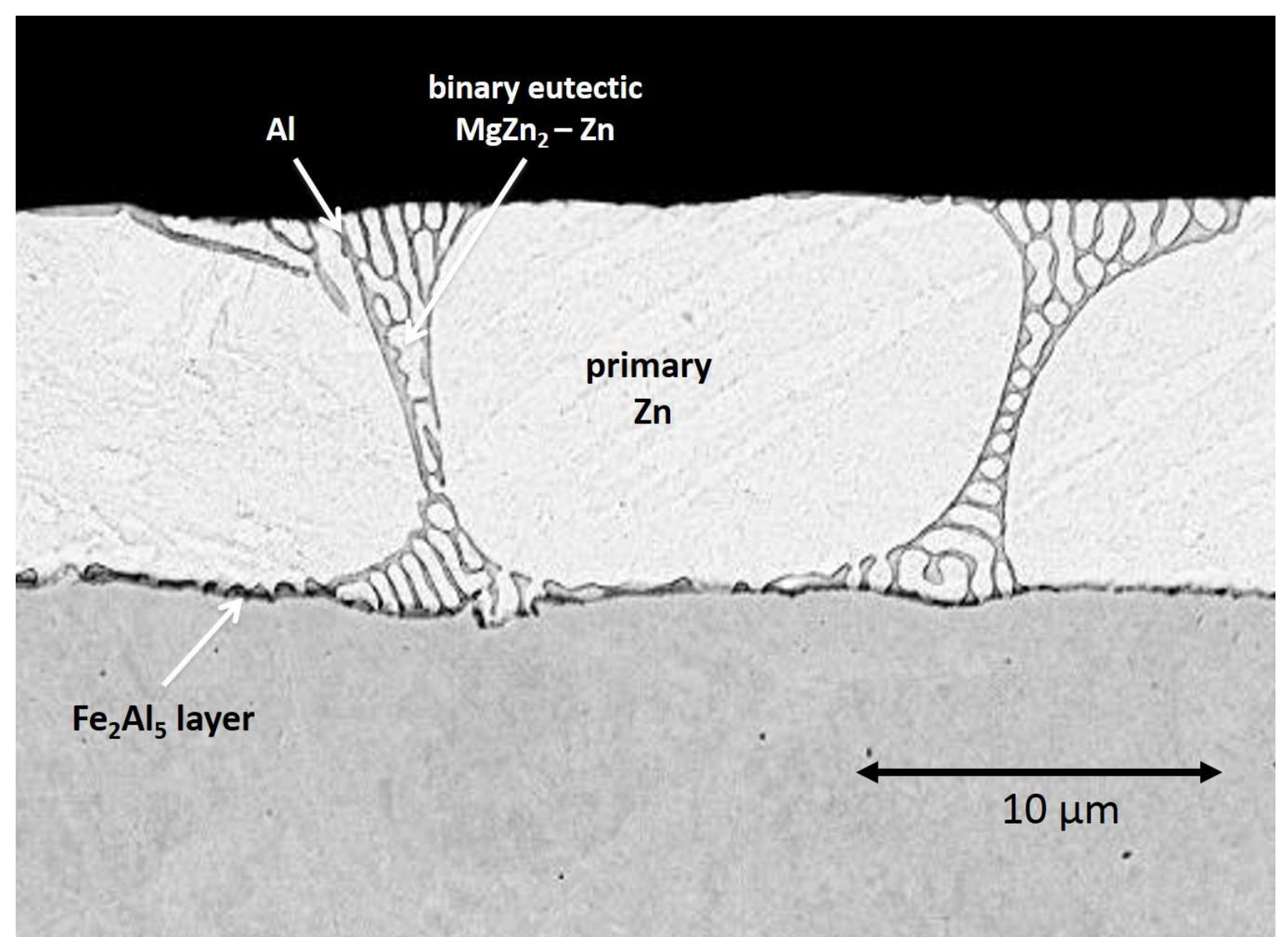


Figure 2

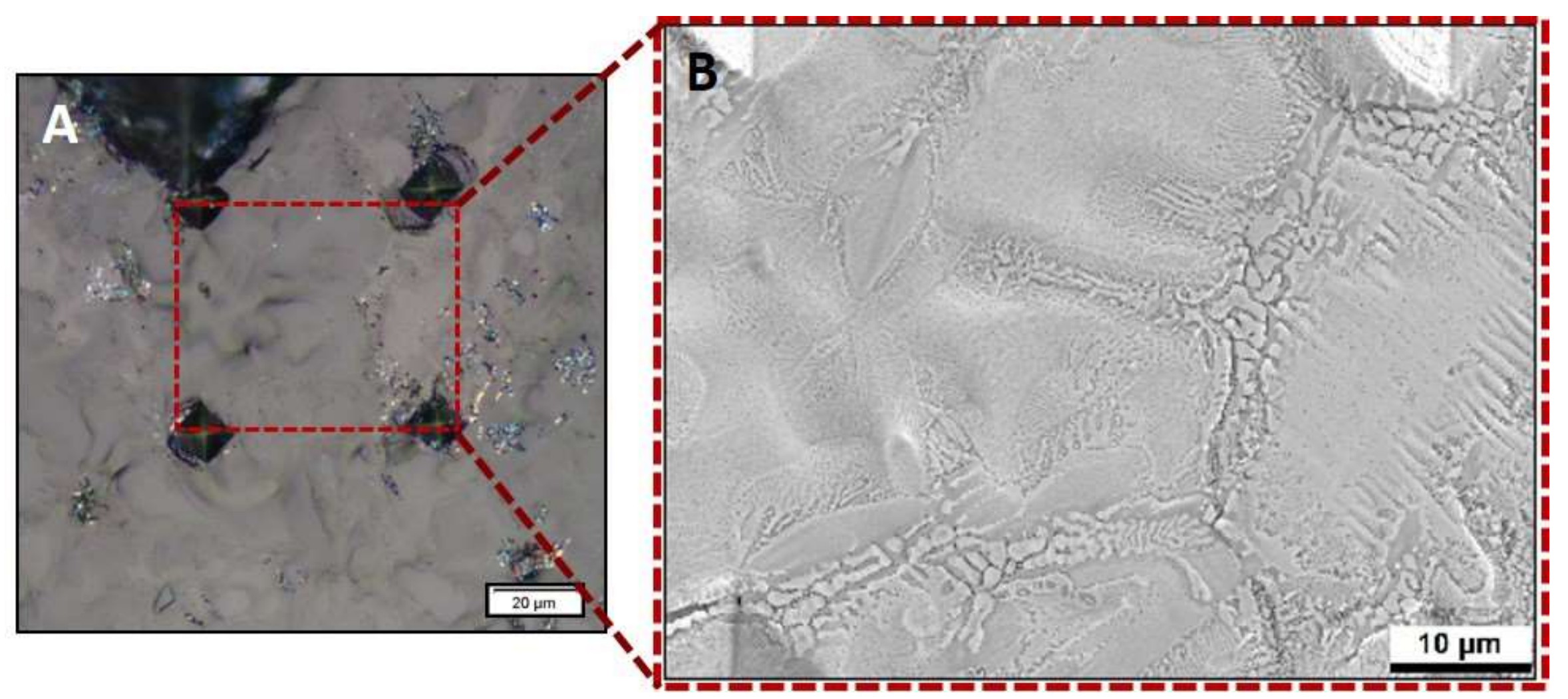


Figure 3
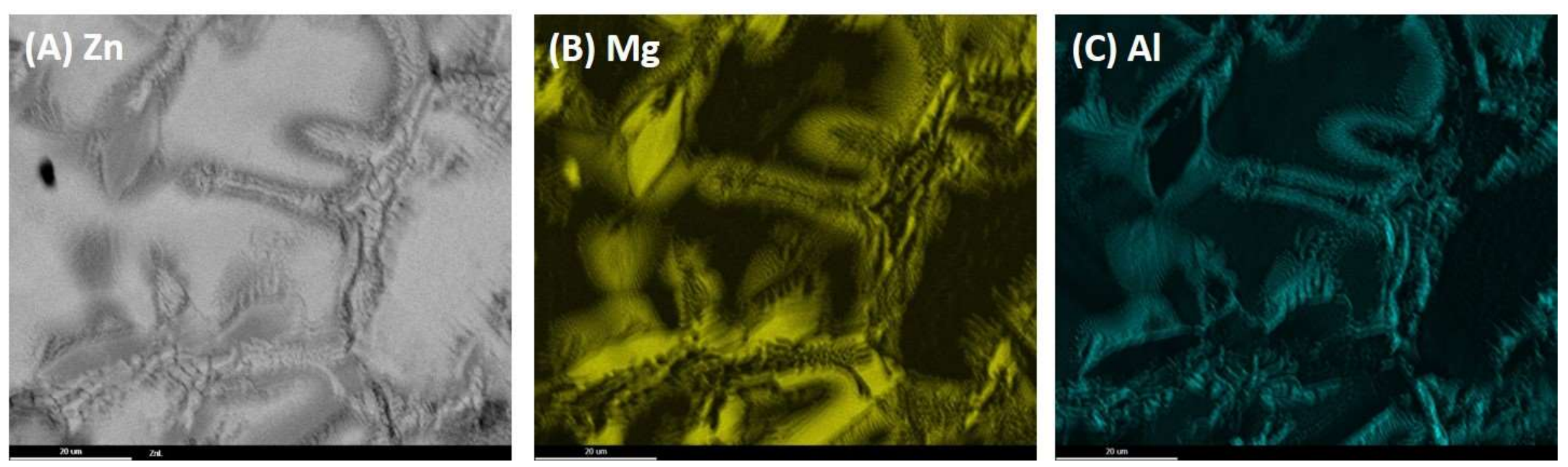
Figure 4
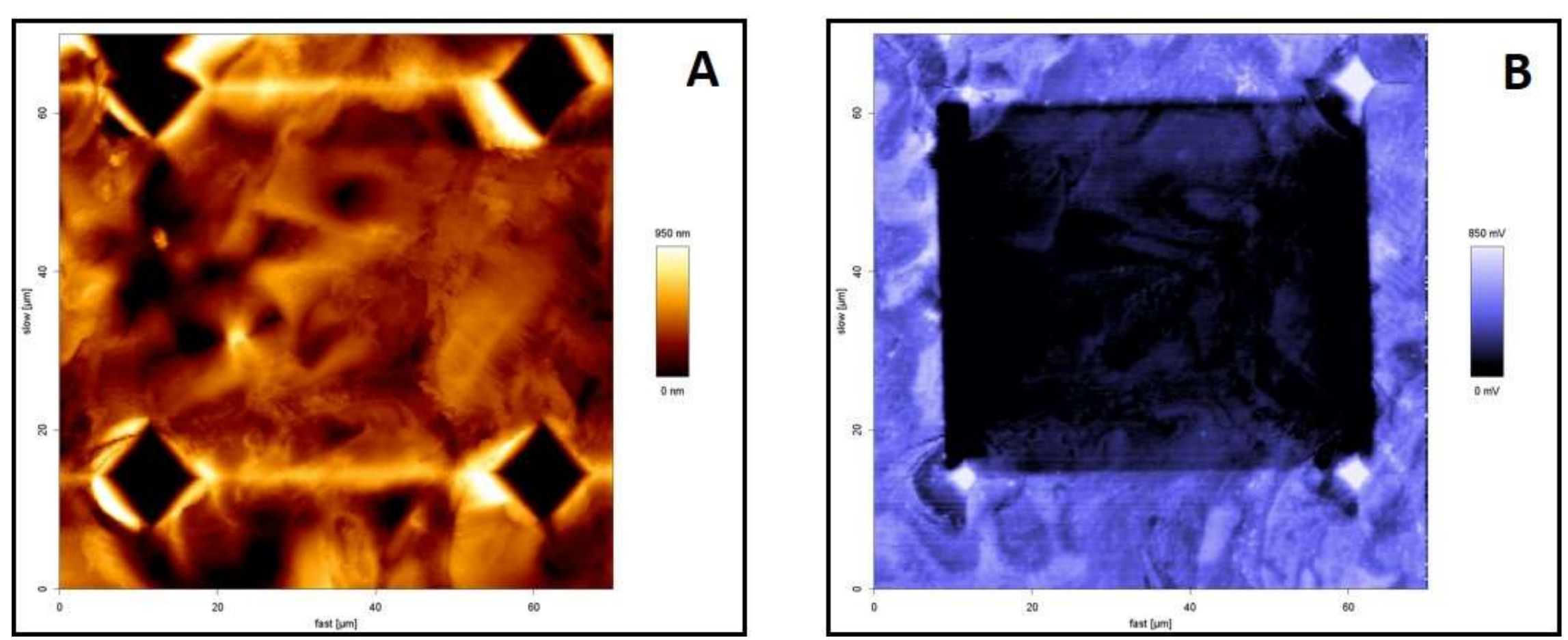
Figure 5

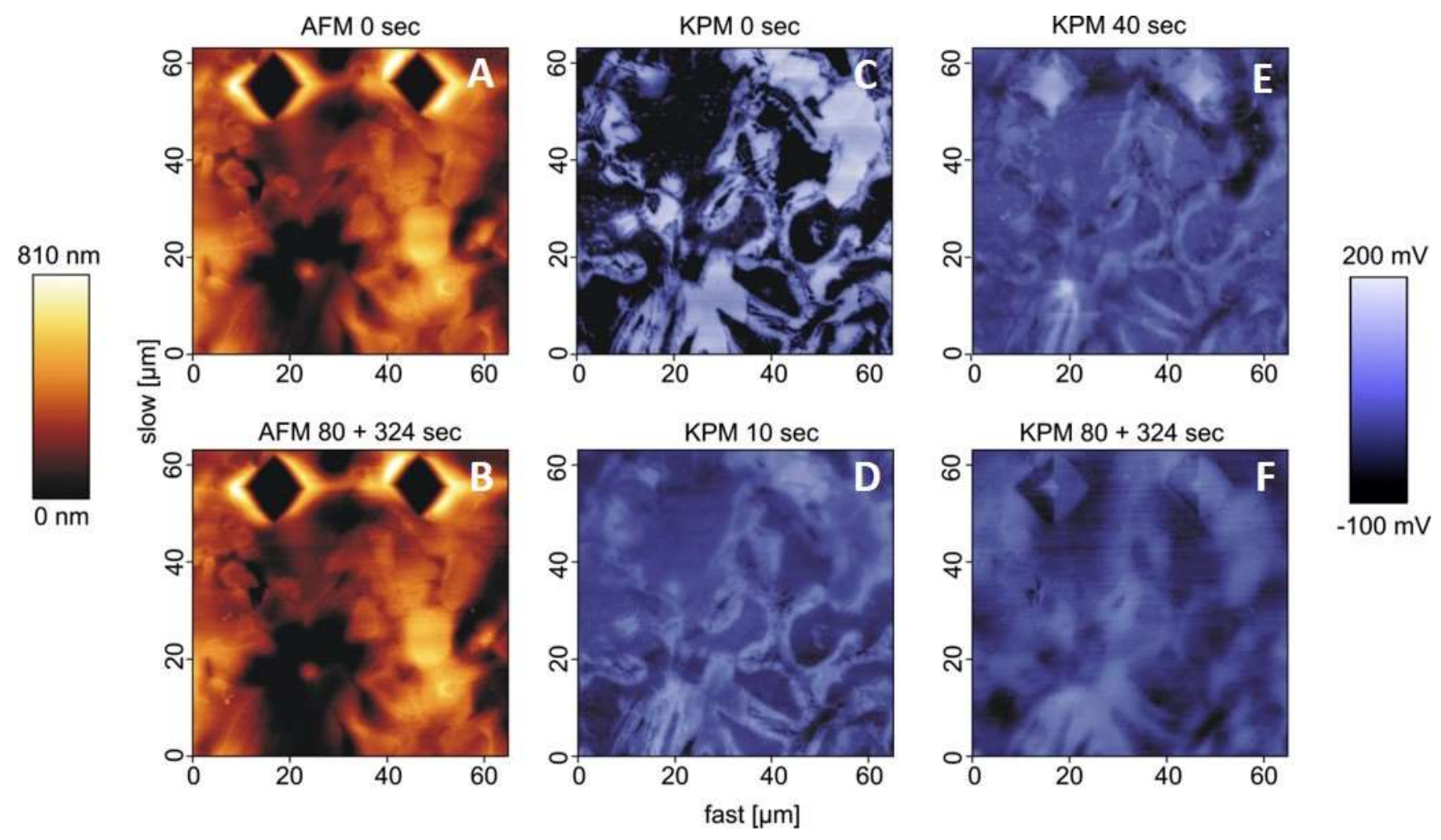




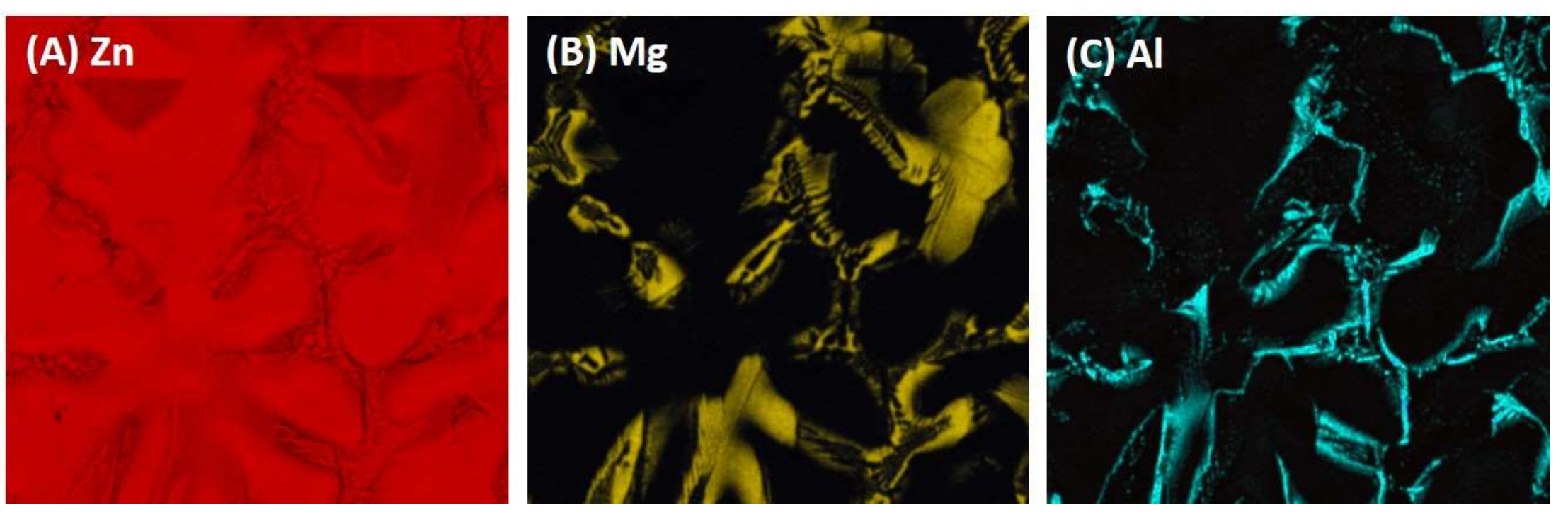


Figure 7

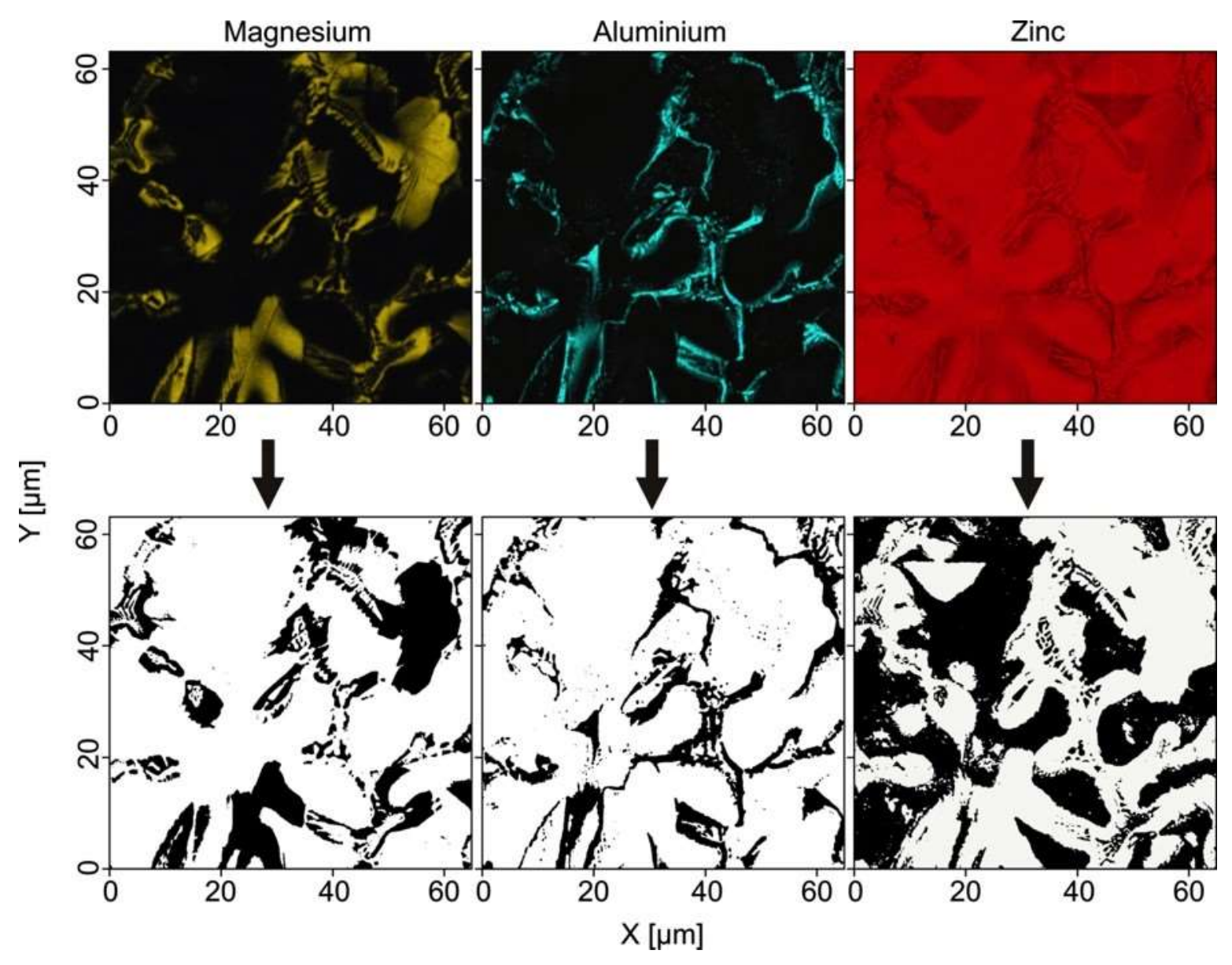




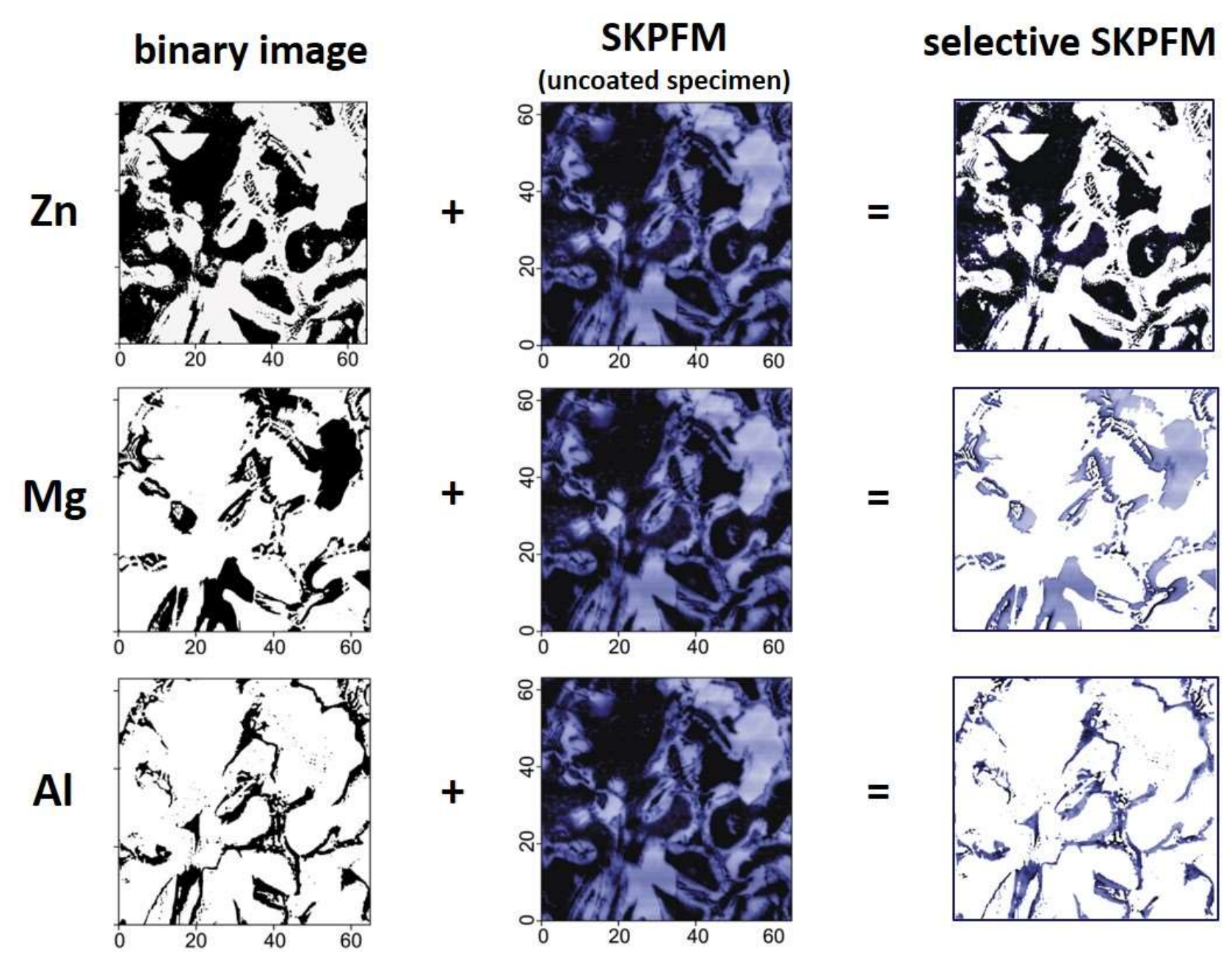




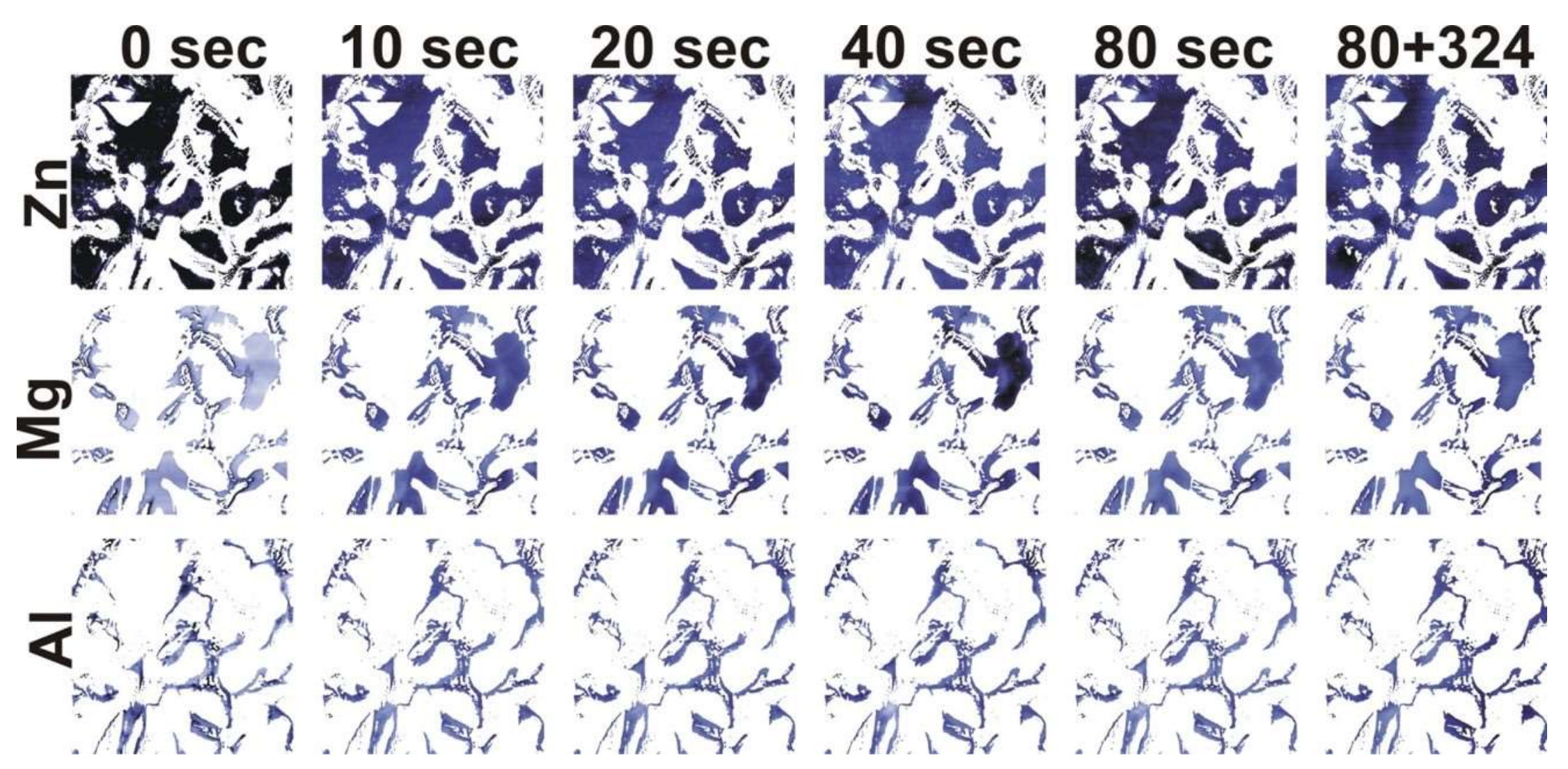


Figure 10
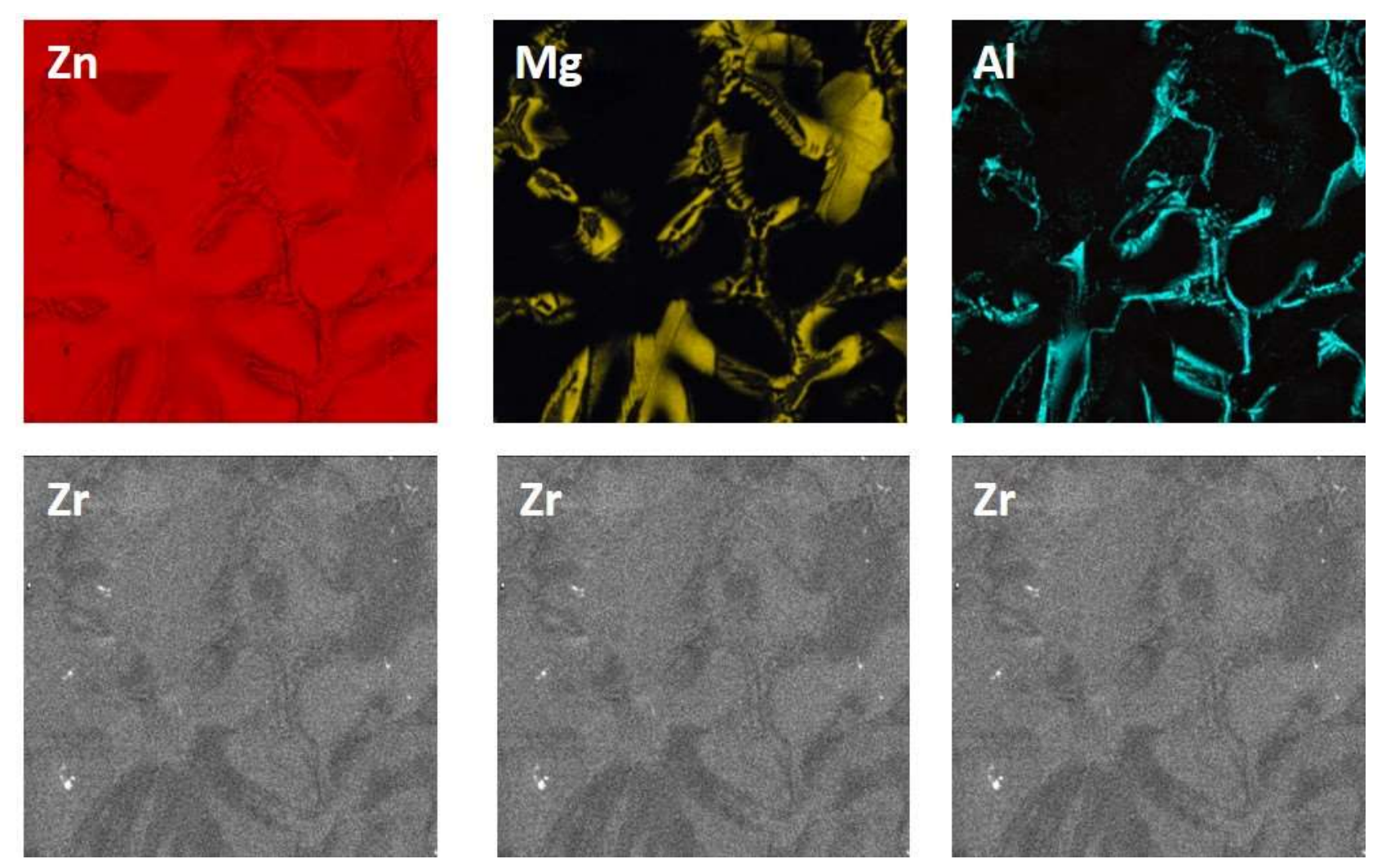
Figure 11

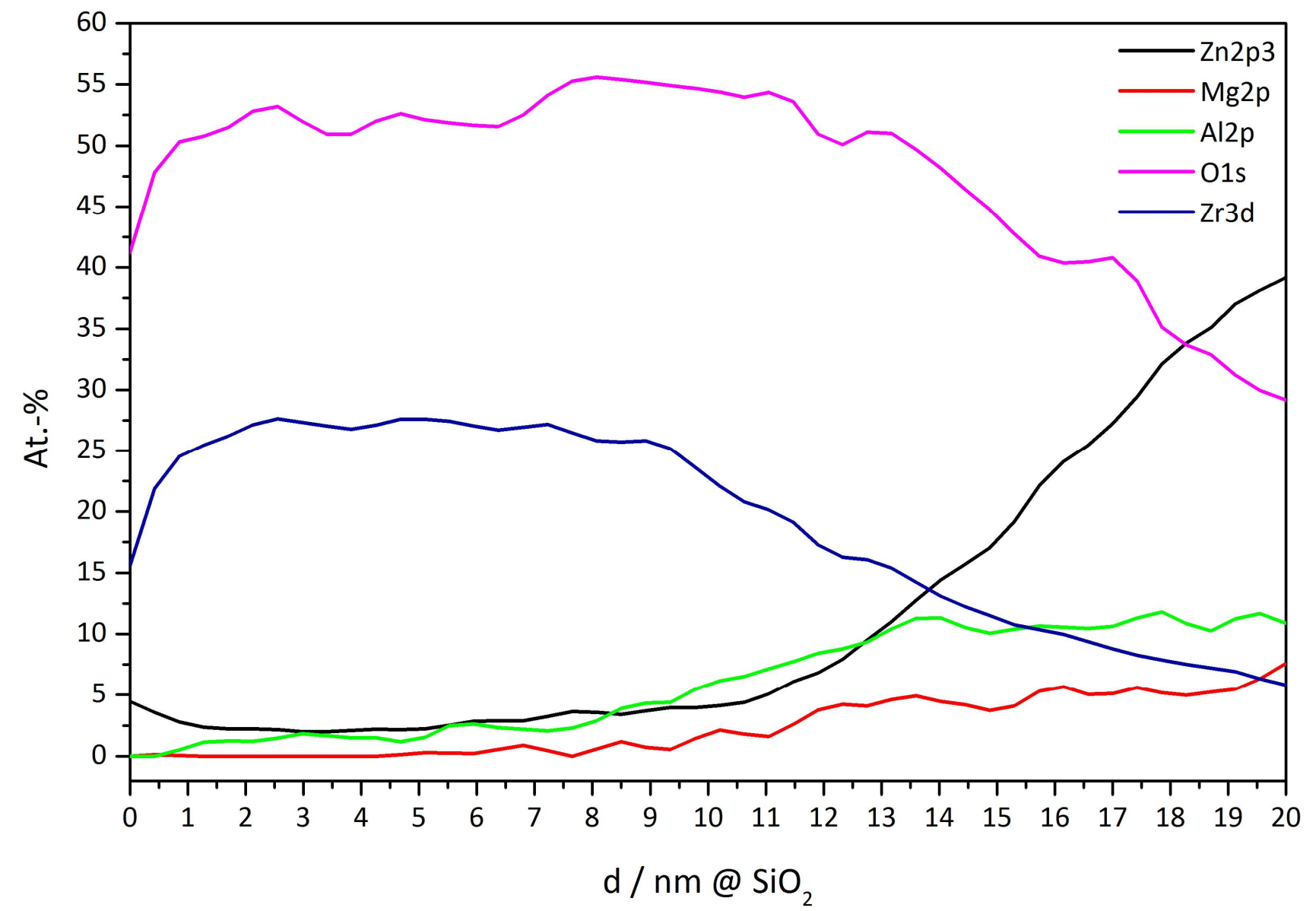


Figure 12

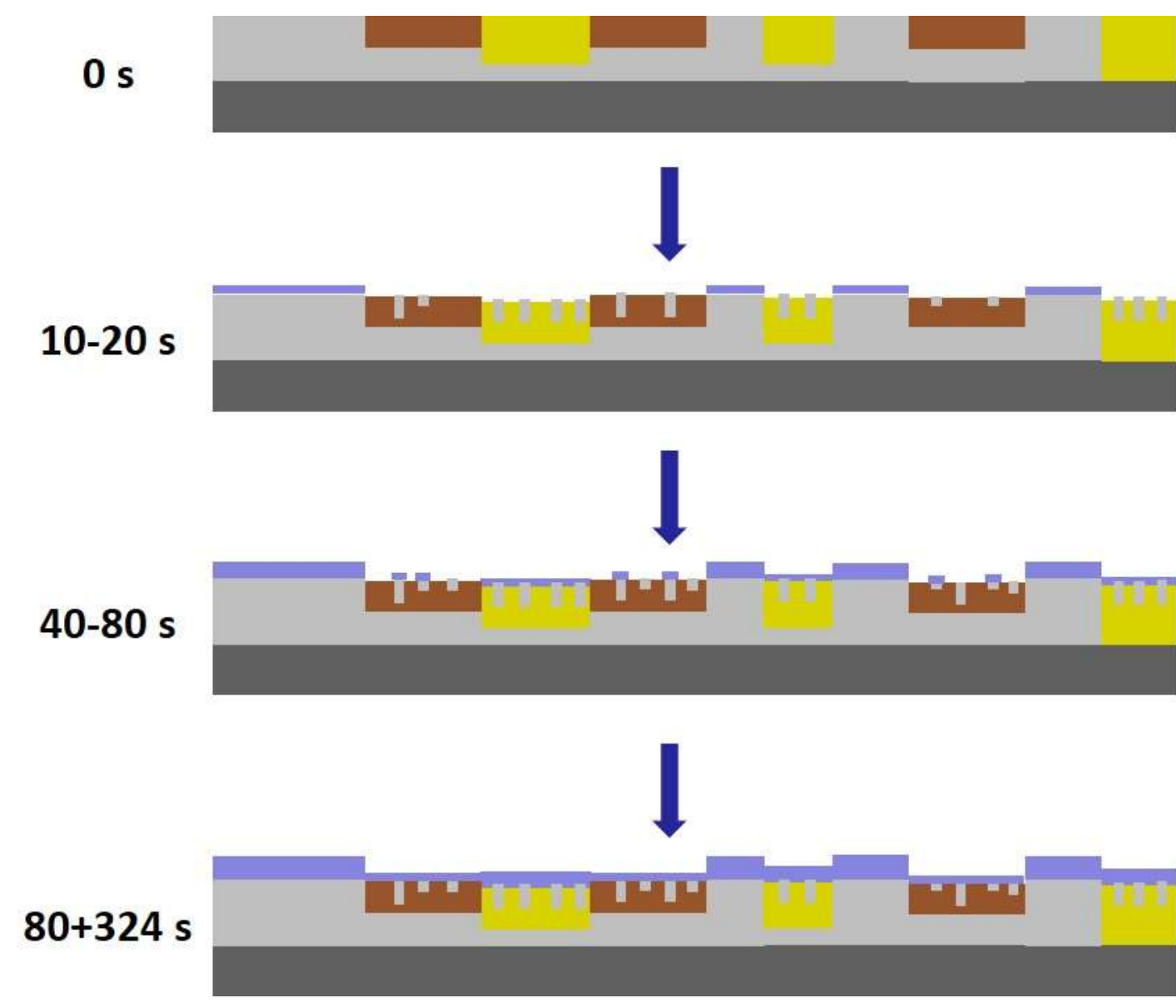

primary Zn

binary eutectic $\mathrm{MgZn}_{2}-\mathrm{Zn}$

Al-rich phase 


\section{DuEPublico}

Duisburg-Essen Publications online

Offen im Denken

Ub $\begin{aligned} & \text { universitäts } \\ & \text { bibliothek }\end{aligned}$

This text is made available via DuEPublico, the institutional repository of the University of Duisburg-Essen. This version may eventually differ from another version distributed by a commercial publisher.

DOI: $\quad 10.1016 /$ j.electacta.2014.05.163

URN: urn:nbn:de:hbz:464-20201119-171929-2

This is the Authors Accepted Manuscript of an article published in: Electrochimica Acta 137 (2014) 65-74. Available online 6 June 2014. The final version may be found at: https://doi.org/10.1016/j.electacta.2014.05.163

(C) $\$$ T) This work may be used under a Creative Commons Attribution cc) NonCommercial - NoDerivatives 4.0 License (CC BY-NC-ND 4.0) 